\title{
Mechanical-thermal simulation of passenger-loaded vehicle seat in severe winter conditions
}

\author{
E.C. Chan, G. Karimi ${ }^{*}$, D. Rose, J.R. Culham \\ Department of Mechanical Engineering \\ University of Waterloo \\ Waterloo, Ontario, Canada
}

Copyright (C) 2004 Society of Automotive Engineers, Inc.

\section{ABSTRACT}

This paper presents a comprehensive steady-state numerical study for an occupant-loaded vehicle seat with internal heating under severe winter conditions. A participant-based postural study showed that the nominal peak occupant seat pressure was $6 \mathrm{kPa}$ on the seat cushion, and $2.5 \mathrm{kPa}$ on the backrest. Uni-axial compression tests also indicated non-linear stress-strain behaviors in seating. Using an internally developed 3-D numerical model, it was found that the thermal resistance from contact and clothing was uniform $\left(h_{c}=144 \mathrm{~W} \cdot \mathrm{K}^{-1} \cdot \mathrm{m}^{-2}\right)$ throughout the occupied regions. Their contribution to the overall thermal resistance was relatively minor, however, compared to that of skin $\left(h_{\text {overall }}=27.2 \mathrm{~W} \cdot \mathrm{K}^{-1} \cdot \mathrm{m}^{-2}\right)$.

The thermal-mechanical simulations were conducted at heat input levels between $20 \mathrm{~W}$ and $80 \mathrm{~W}$, using I-DEAS 10 and the TMG package as the simulation platform. Comparisons was also made between occupied seat with deflected and non-deflected mesh. The occupant deflection helped reduce the thermal resistance in the occupied region, which resulted in a slight decrease in heater temperature, accompanied by an increase in the average surface temperature, compared to corresponding undeformed results.

\section{INTRODUCTION}

Thermal comfort has a substantial influence on driving experience and safety, particularly under sever winter conditions. Although, in address the issue, automotive manufacturers have been introducing internally heated

*Affiliated with the Department of Chemical Engineering, Shiraz University, Shiraz, Iran. seats in select models for the past decade, only a limited number of studies could be found on the thermal-mechanical interaction between the heated seat and its occupant. This study serves as a starting point of a detailed analysis on heat transfer and mechanical deformation.

The present research consists of three components. First, the elastic characteristics of the seat construction materials, most notably foamed rubber polyurethane (FRPU), were to be determined. This was accomplished through uni-axial compression testing of prepared samples. Second, the occupant seating pressure was acquired, through a participant-based postural study, to model a realistic mechanical loading condition. Most importantly, the thermal simulation required proper prescription of the ambient conditions and human physiology. Additional simplifications were also needed to accommodate software and computational restraints. The ultimate goal of the study was to examine the changes in steady-state seat temperature distribution in the presence of an occupant, as well as elastic deformation.

\section{SEAT CONSTRUCTION}

A special internally heated / ventilated seat prototype was used throughout the research. The FRPU defined the basic seat structural features and also provided cushioning for the occupant. Part of the seat FRPU was carved out to accommodate the heater / ventilation unit, which comprised of an electrical heater, a fan blower, a sheet of reticulated foam and a porous spacer, covered with perforated leather. The heater, located between the reticulated foam and the porous spacer, was also highly permeable. This unique design allowed the occupant to reach thermal comfort quickly. A schematic of the seat is presented on Figure 1. 


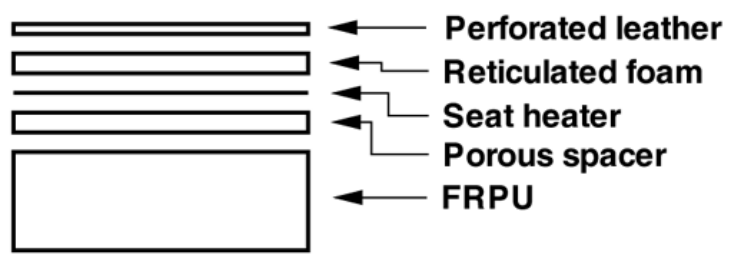

Figure 1: Schematic of the internally heated/ventilated seat construction used in this study.

\section{NON-LINEAR ELASTICITY MEASUREMENTS}

As mentioned above, there are four materials that make up the seat system:

- FRPU: material which defines the structure of the vehicle seat,

- Porous spacer: a highly-porous fibrous sheet designed for structural support,

- Reticulated foam: a layer of sponge that buffers between the perforated leather and porous spacer, and

- Perforated leather: a thin $(1 \mathrm{~mm})$ layer of vinyl-treated animal hide with uniform perforations to allow airflow.

The foamy structure of the construction materials gives rise to their non-linear elastic behavior, for the structure buckles under load. This results in three distinctive elastic responses before, during, and after buckling occurs. This behavior was reported in Ragan et al. [9] and Todd et al. [10] for FRPU. The three phases are appropriately termed bending, buckling, and collapse, and they are identified on Figure 2. Perforated leather, due to its thickness, was assumed to experience no deflection while undergoing compression.

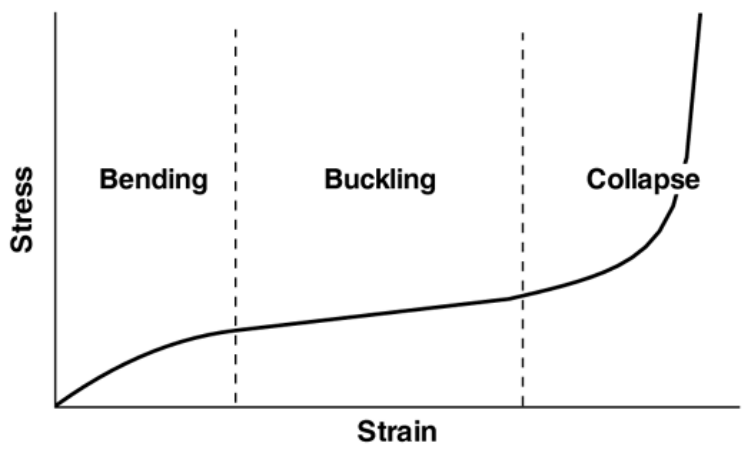

Figure 2: Stress-strain relationship of typical foamy materials.

To estimate the extent of deflection from compressive loading, a circular sample $\left(A=0.3 \mathrm{~m}^{2}\right)$ of each material was prepared and stacked up according to the schematic on Figure 1. They were then subjected to distributed loads $10 \mathrm{~kg}(3.3 \mathrm{kPa})$ and $20 \mathrm{~kg}(6.6 \mathrm{kPa})$. The corresponding deflection level for FRPU jumped from $2.2 \%$ of the original thickness at $10 \mathrm{~kg}$ to $27 \%$ at $20 \mathrm{~kg}$ (Figure 3). Meanwhile, the strain level for the porous spacer increased from $11 \%$ to $26 \%$, and from $16 \%$ to $56 \%$ for reticulated foam. All three materials exhibited non-linear elastic behavior, and a more accurate and detailed characterization of the stress-strain relationships was necessary.
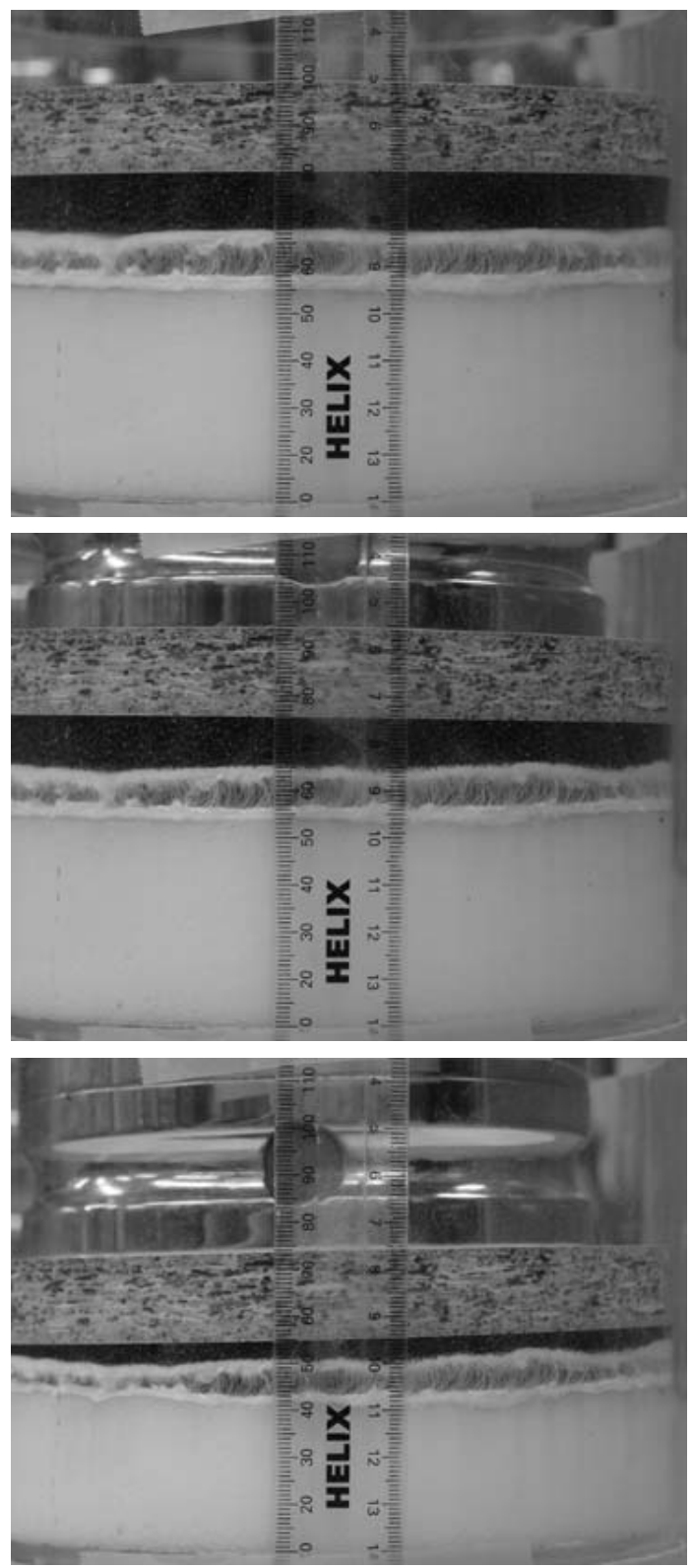

Figure 3: Visualization of seat material compression under (left) no load, (middle) $10 \mathrm{~kg}(3.3 \mathrm{kPa})$, and (right) $20 \mathrm{~kg}(6.6 \mathrm{kPa})$.

\section{EXPERIMENTAL SETUP}

Uniaxial compression tests were performed to determine the stress-strain relationship for each material. Individual circular samples $\left(A=0.07 \mathrm{~m}^{2}\right)$ were prepared and, if necessary, leveled on base plates with Plaster of Paris. A light, rigid circulate plate of identical size was also cut to ensure uniform loading on the sample. The sample was secured on an Instron 4206 tensile/compression tester, 
and a CCTM compression load cell was used to register the compressive force. To reduce noise in the data, the compression tests were performed at a sampling rate of $0.125 \mathrm{~Hz}$, while the head speed varied from 2 to $5 \mathrm{~mm} \cdot \mathrm{min}^{-1}$, depending on the thickness of the sample.

Figure 4 displays the stress-strain curves for each material used in the study. The three phases, namely bending, buckling, and collapse, could be identified. Unlike FRPU and reticulated foam, the porous spacer exhibited more resilience, characterized by the linear behavior before and after buckling. It was also evident that the reticulated foam collapsed in multiple stages. Strain softening (i.e., $\partial \sigma / \partial \varepsilon<0$ ) was also observed at the early stages of buckling.

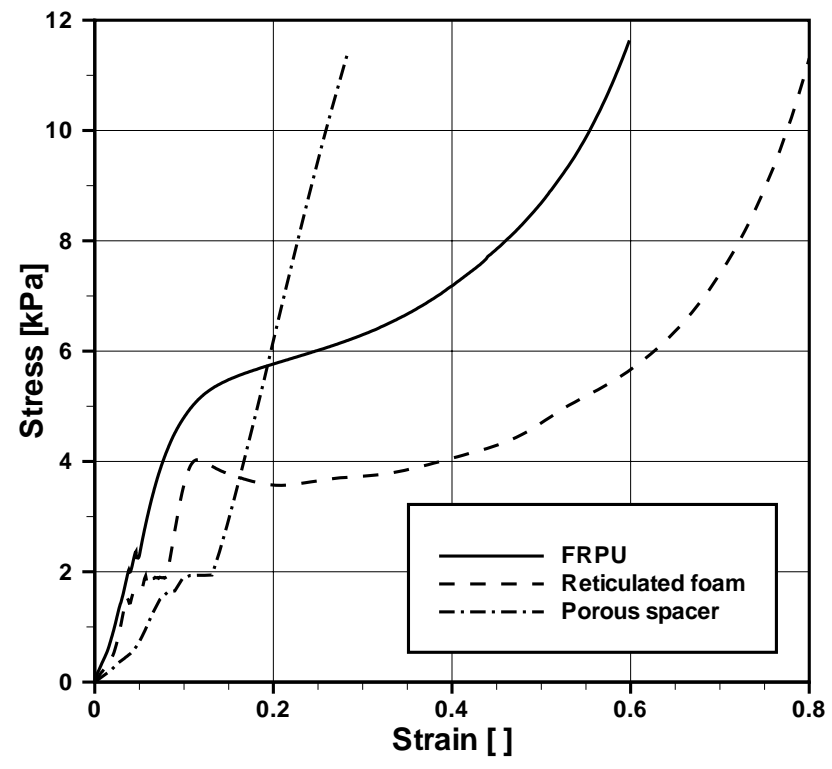

Figure 4: Measured stress-strain curves for FRPU, reticulated foam, and porous spacer.

\section{PARTICIPANT-BASED POSTURAL STUDY}

The objective of the postural study was to obtain a representative occupant imprint and load distribution on the vehicle seat. The pressure was measured using two Tekscan pressure mats, which were secured on the seat cushion and backrest, illustrated on Figure 5. Ten participants were chosen and 10 to yield a representative distribution on gender, age, and body types. Each participant was informed the nature of the study, and was instructed to assume a neutral seating posture, as illustrated on Figure 6.

The total seating period was five minutes for each participant, and a time-average pressure distribution was taken. The individual results were used to obtain the representative distribution, as shown on Figure 7 . With the seat pressure distribution known, and the elastic properties measured, it was now possible to proceed to the perform simulations to estimate the amount of seat deformation due to occupant loading.

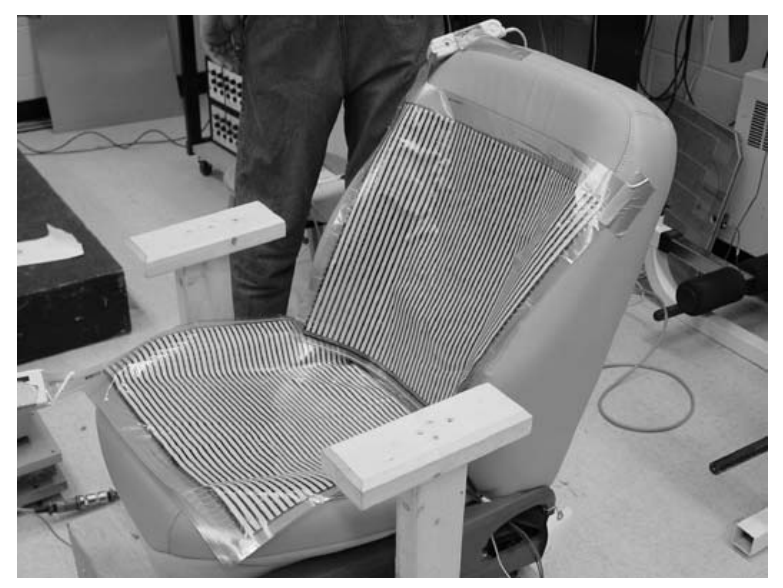

Figure 5: Covering the seat prototype with Tekscan pressure mats.

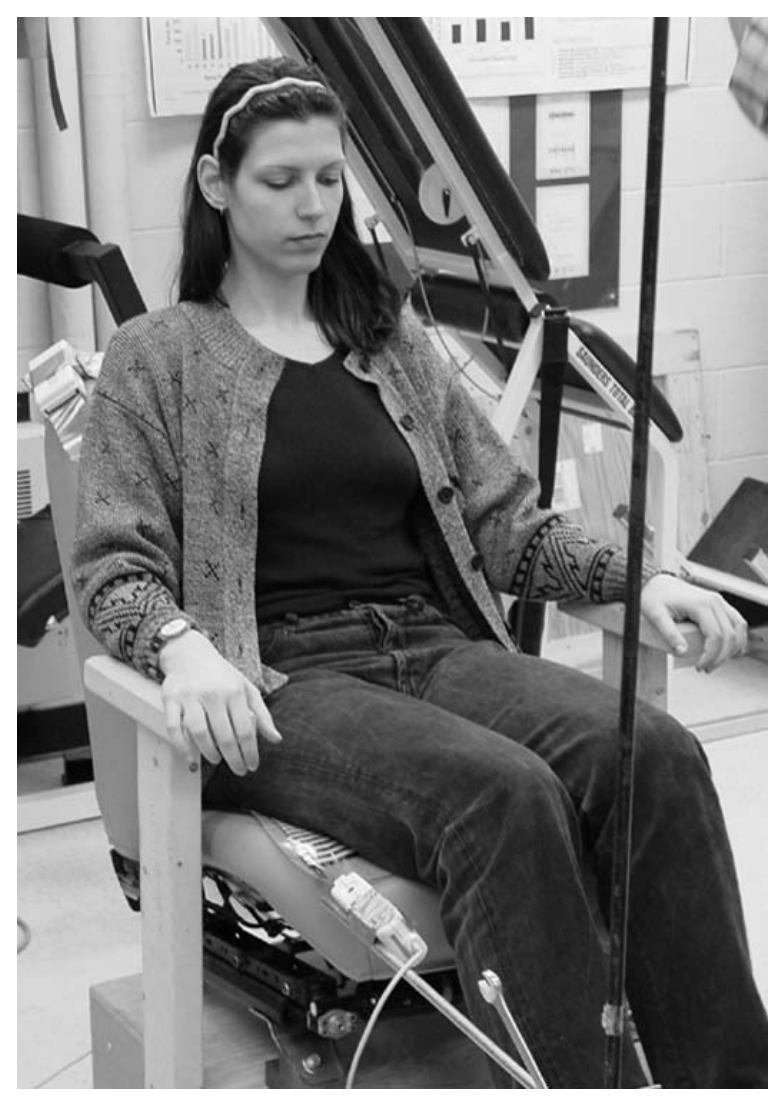

Figure 6: A participant maintained a neutral seating posture during the seating period.

\section{MECHANICAL SIMULATION}

In the mechanical simulation, the occupant pressure distribution was applied as a load boundary condition, and the elastic response was dictated by the stress-strain relationship of the three construction materialsi 


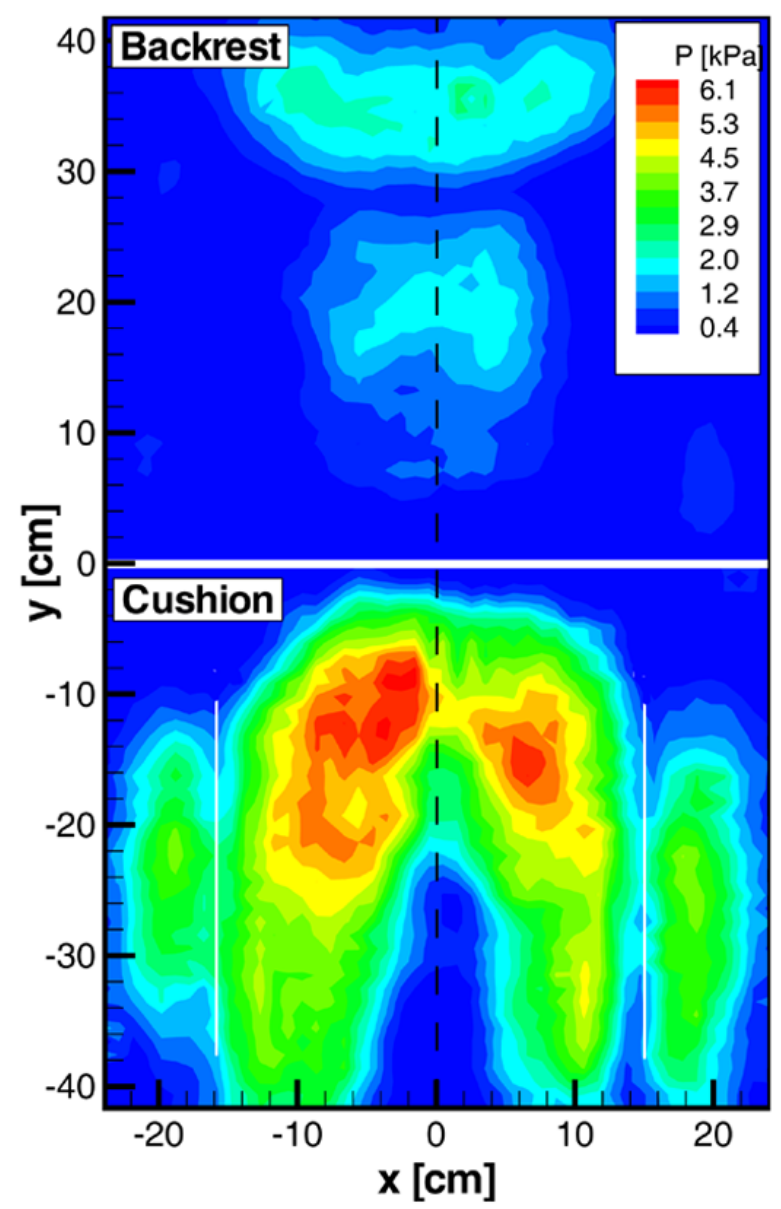

Figure 7: Seat occupant pressure distribution averaged over 10 participants.

To remedy these problems, the experimental pressure data were divided into discrete regions. The readings from each pressure sensor were converted to an average reading over the particular region on which the sensor resided. For convenience, the cushion imprint was divided into three contour levels, and two were assigned for the backrest. Figure 8 illustrates the contourized pressure distributions. To further simplify the model, the contourized distribution was rendered symmetric and subsequently drafted onto the seat CAD files.

The effective Young's modulus for each material were then calculated by taking the secant slope at each contourized pressure level on the stress-strain curve with respect to the origin. The results are presented on Table 1. The effective properties, 15 in total, were assigned to each contour level. Meanwhile, the Poisson's rations for all materials were assigned a value of 0.1 [9].

The stress distribution from the simulation is presented on Figure 9. Pressure spikes were noted along the contourized boundaries. This phenomenon was a result from the discretized pressure load, and could be alleviated by introducing additional contour levels into the CAD model. This, however, would increase the number of

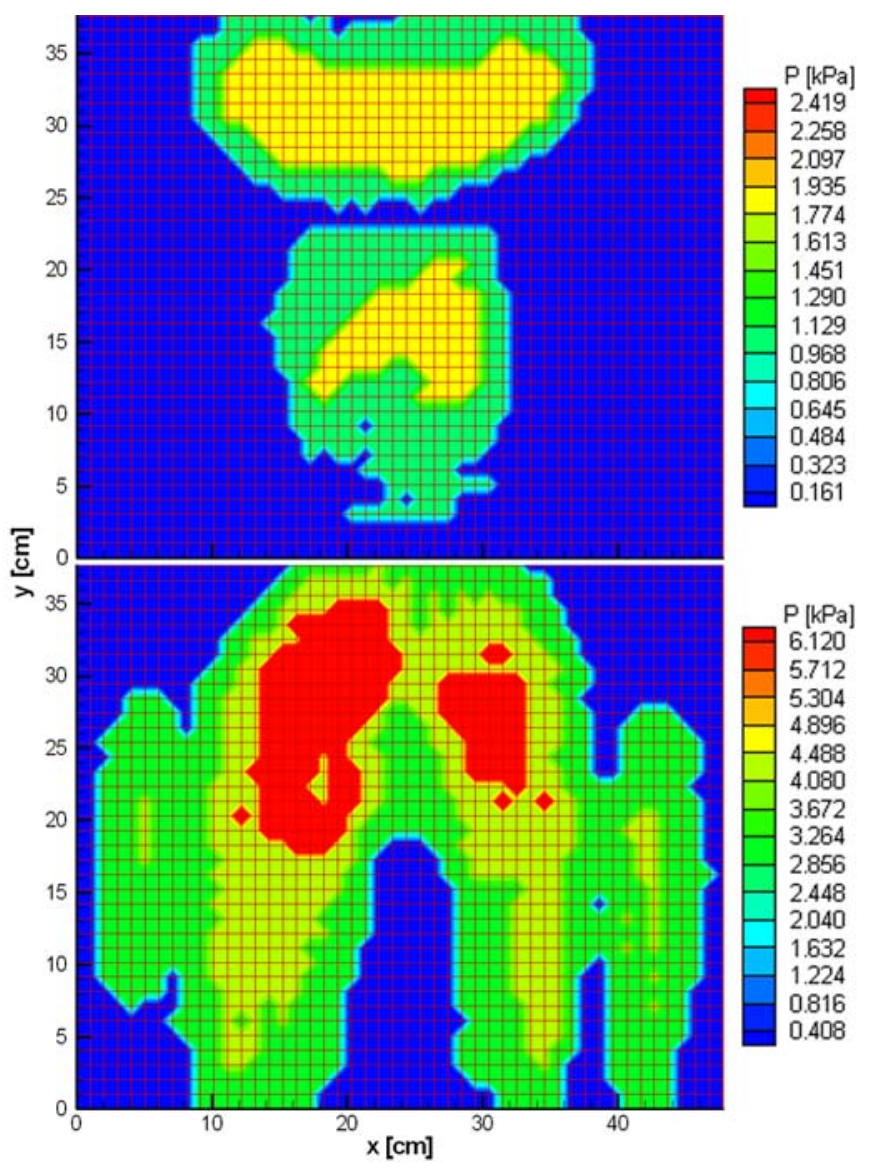

Figure 8: Contourized seat pressure distributions.

Table 1: Effective Young's moduli for FRPU, reticulated foam, and porous spacer at different contourized loads

\begin{tabular}{lccc}
\hline Load [kPa] & FRPU & R. foam & Spacer \\
\hline 1.08 (backrest) & 31.8 & 56.8 & 21.5 \\
1.81 (backrest) & 34.1 & 65.0 & 25.3 \\
3.10 (cushion) & 18.8 & 77.9 & 32.8 \\
4.19 (cushion) & 9.44 & 8.60 & 38.2 \\
5.48 (cushion) & 9.70 & 8.37 & 29.8 \\
\hline
\end{tabular}

effective Young's moduli considerably, and drafting the refined pressure contours onto the CAD model would add another level of complexity. Figure 10 shows the corresponding simulated displacement. In addition to the displacement within the occupied regions, both top edges along the cushion were also affected by the load, due to loading from the legs to the cushion sides. Considering that the simulation deflection was at an acceptable level, the current contourization approach was deemed sufficient to be employed in the combined thermal-mechanical study.

\section{COMBINED THERMAL-MECHANICAL SIMULATION}

The mechanical simulation gave rise to a deformed mesh which could be carried into I-DEAS TMG simulation 
package. A number of concerns were addressed in formulating the combined model. First and foremost were the potential changes in thermal conductivity of the

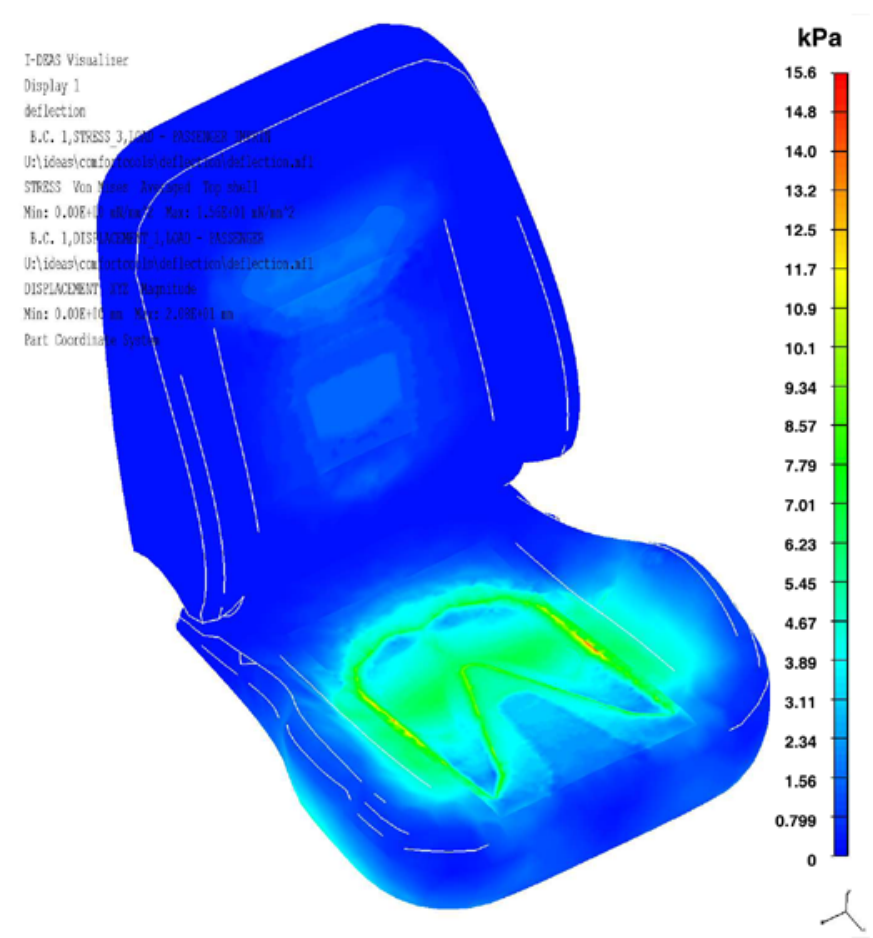

Figure 9: Simulated stress distribution based on contourized occupant seat pressure.

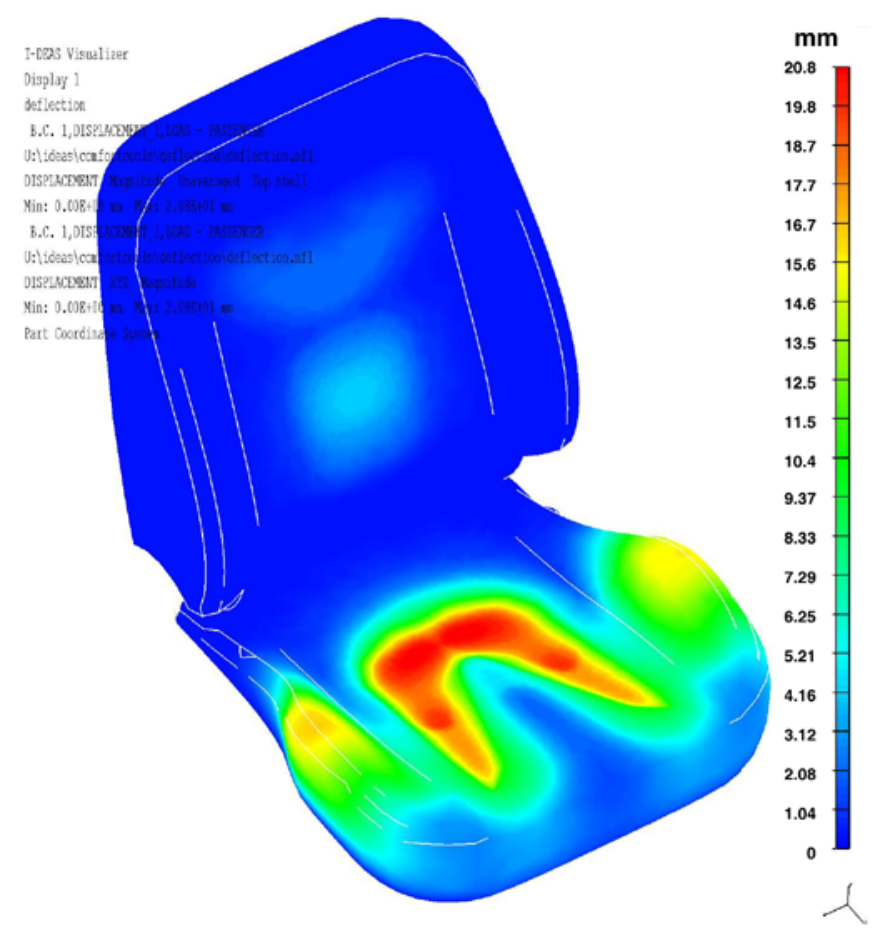

Figure 10: Simulated deflection based on contourized occupant seat pressure. foam materials due to deflection. As the air in insulation was displaced by compression, the conductivity of the insulation would also increase. According to Figure 4, at the maximum occupant load of $5.5 \mathrm{kPa}$, both FRPU and the porous spacer still retained over $80 \%$ of their original volumes. Hence the conductivity was not expected to deviate greatly from the undeformed values.

The exception was reticulated foam. Not only was it reduced to $40 \%$ of its original volume under the same load, while it was heated from below by the heater, its conductivity was also altered by natural convection by a certain degree. An effective thermal conductivity was assigned to instead of resolving the heat transfer process at the pore scale. Using the data compiled by Cheng [3], an order-of-magnitude analysis indicated that the effective conductivity was about $0.2 \mathrm{~W} \cdot \mathrm{K}^{-1} \cdot \mathrm{m}^{-1}$. Table 2 shows all the thermal conductivity values used in the thermal simulation, including human skin [1].

Table 2: Thermal conductivity for FRPU, reticulated foam, porous spacer, perforated leather, and human skin.

\begin{tabular}{lc}
\hline Thermal conductivity & {$\left[\mathrm{W} \cdot \mathrm{K}^{-1} \cdot \mathrm{m}^{-1}\right]$} \\
\hline FRPU & 0.033 \\
Reticulated foam & 0.2 \\
Porous spacer & 0.04 \\
Perforated leather & 0.08 \\
Human skin & 0.501 \\
\hline
\end{tabular}

The next issue was the modeling human physiology in I-DEAS. Detailed physiological models were available $[4,5,8]$ by taking into account heat generation from the body and heat loss by perspiration, radiation, convection, etc.. Karimi et al.[7] had shown that, using a variation of the Burch model [2] - the core temperature core temperature remained almost constant under severe weather conditions. Given that clinical hypothermia occurs when the core temperature goes below $2^{\circ} \mathrm{C}$ from normal, the occupant physiological model could be further simplified, by using a constant temperature source at $\left(37^{\circ} \mathrm{C}\right)$ to represent the body core, as documented in Karimi et al.[6]. Meanwhile, the skin was assumed to have a uniform average thickness of $1.5 \mathrm{~cm}$.

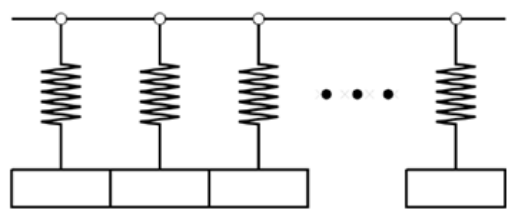

Body core

Overall thermal resistance (skin, clothes, contact)

Seat surface (occupied region)

Figure 11: Schematic for the human physiological model, after Karimi et al.[6].

The schematic of the present human physiological model is shown on Figure 11. In addition to the skin layer, the model also considered contributions of clothing and contact pressure with the seat. An overall 
thermal resistance was formed based on the sum of the three resistances, which could be calculated from their respective values conductivity and heat transfer coefficient. At the end of each thermal resistance was the occupied surface of the seat.

The equivalent thermal resistance for human skin was $0.299 \mathrm{~W} \cdot \mathrm{K}^{-1}$. Meanwhile, the combined heat transfer for clothing and contact, computed using the 3-D model of Karimi et al.[6], was $144 \mathrm{~W} \cdot \mathrm{K}^{-1} \cdot \mathrm{m}^{-2}$ throughout the occupied region (Figure 12), and the corresponding thermal resistance was $0.0690 \mathrm{~W} \cdot \mathrm{K}^{-1}$. The overall thermal resistance was therefore $0.368 \mathrm{~W} \cdot \mathrm{K}^{-1}$, which was equivalent to a heat transfer coefficient of $27.2 \mathrm{~W} \cdot \mathrm{K}^{-1} \cdot \mathrm{m}^{-2}$. The overall thermal resistance was much closer to that of skin, indicating that the effects of clothing and contact were only secondary.
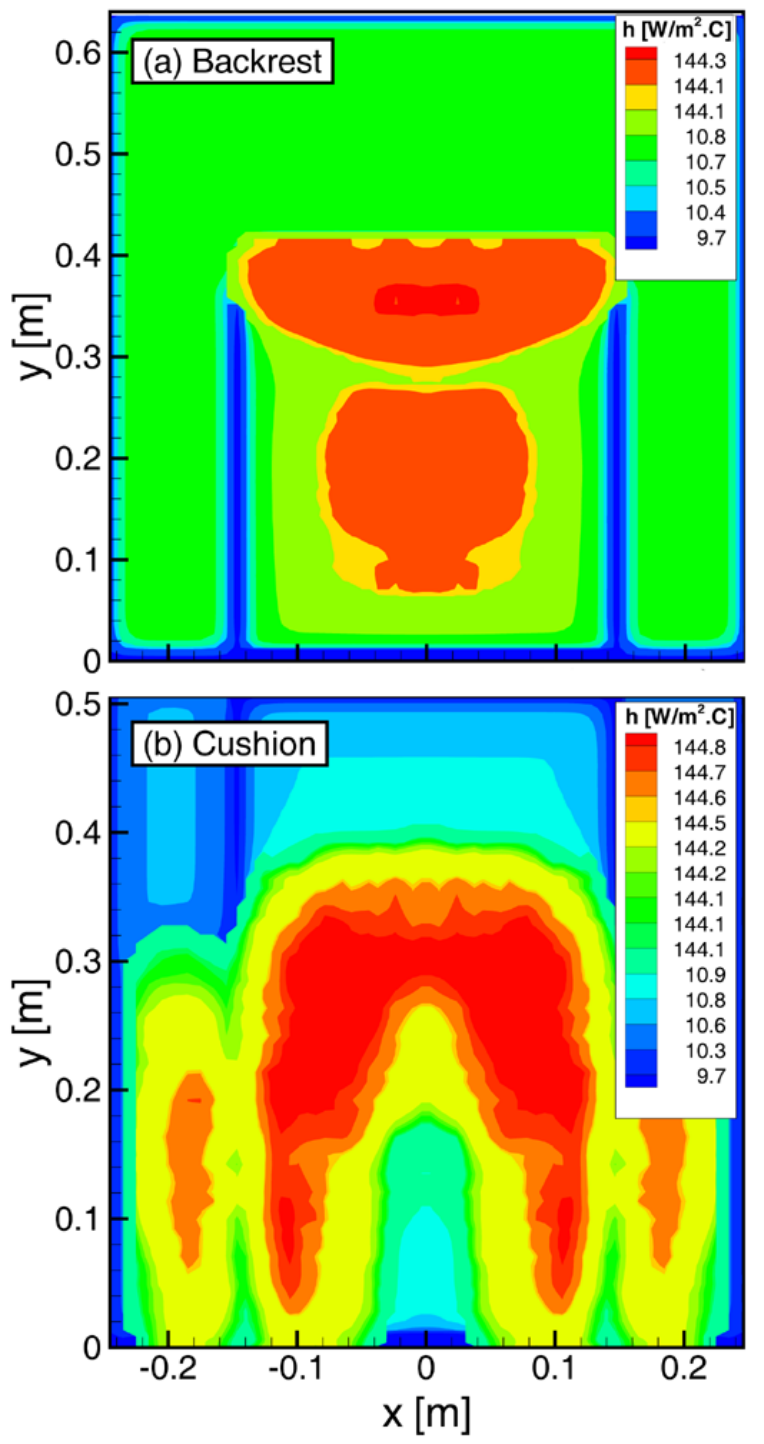

Figure 12: Distribution of heat transfer coefficient on the occupant-covered seat surface, based on Karimi et al.[6].

The final issue concerned the incorporation of the mechanical simulation into the heat transfer simulation.
As the nature of this study was to combine the two aspects, the thermal simulations would, by default, employ the deformed mesh from the mechanical simulation. On the other hand, it was also of interest to find out if the mechanical simulation would provide any additional insight to the steady-state temperature distribution. Consequently, another identical set of thermal simulations were executed using only the undeformed mesh.

\section{OCCUPIED SEAT TEMPERATURE DISTRIBUTION WITHOUT DEFLECTION}

The simulations were run at seat heat input power levels of $20 \mathrm{~W}, 40 \mathrm{~W}, 60 \mathrm{~W}$, and $80 \mathrm{~W}$. To simulate sever winter conditions inside a vehicle cabin, the ambient temperautre was set to $0^{\circ} \mathrm{C}$, and the heat transfer coefficient from all unoccupied seat surface to the ambient was set to $15 \mathrm{~W} \cdot \mathrm{K}^{-1} \cdot \mathrm{m}^{-2}$ to account for effects of natural convection and radiation.

The steady-state surface temperature distributions at the four input power input are presented on Figure 13 for the undeformed occupied seat. There was an observable low temperature region between the buttock and leg regions. The lack of insulation (FRPU) in said regions resulted in a lower surface temperature. The average temperatures for the occupied surface and the seat heater are presented on Table 3.

\section{OCCUPIED SEAT TEMPERATURE DISTRIBUTION WITH DEFLECTION}

This set of simulation incorporated the results from the mechanical simulation, i.e., the deformed seat, into the thermal simulation. The thermal boundary conditions remained unchanged. The temperature distribution for all four cases are shown on Figure 14. Meanwhile, the average temperature values for the occupied surface and the seat heater are summarized on Table 4. The relative deviation between the deformed and undeformed model was calculated based on the corresponding temperature difference with respect to the deformed model temperature. They are presented on Table 5.

The most notable difference between the two model results was that the deformed model yielded a much lower temperature than the undeformed model (between $5.68 \%$ to $13.3 \%$ ). The deflection on the reticulated foam caused a reduction in thermal resistance. This, in turn, facilitated local heat transfer and resulted in a lower heater temperature. The deformed model also reported a slightly higher surface temperature. This was also a consequence of deflection, which, in addition to reducing the local thermal resistance, brought the seat surface closer to the heat source. However, like the undeformed model, a narrow band of low-temperature region could also be observed, where the amount of FRPU was reduced along 
the underside of the cushion. Furthermore, while most of the differences between the two models were observed in the cushion region, the backrest, being almost intact from passenger loading (maximum contourized load was only $1.81 \mathrm{kPa}$ ), the corresponding temperature change was also relatively small, less than $1 \%$ in all cases. This was possibly a result of the human body core moderating the surface temperature.

Table 3: Average temperature over (top) the occupied surface, and (bottom) the seat heater for the undeformed occupant model.

\begin{tabular}{lllll}
\hline Occupied surf. temp. $\left[{ }^{\circ} \mathrm{C}\right]$ & $20 \mathrm{~W}$ & $40 \mathrm{~W}$ & $60 \mathrm{~W}$ & $80 \mathrm{~W}$ \\
\hline Backrest & 36.2 & 40.3 & 44.3 & 48.4 \\
Cushion & 37.9 & 41.8 & 45.7 & 49.5 \\
Overall & 37.5 & 41.4 & 45.3 & 49.3 \\
\hline
\end{tabular}

\begin{tabular}{lllll}
\hline Seat heater temp. $\left[{ }^{\circ} \mathrm{C}\right]$ & $20 \mathrm{~W}$ & $40 \mathrm{~W}$ & $60 \mathrm{~W}$ & $80 \mathrm{~W}$ \\
\hline Backrest & 38.5 & 51.0 & 63.5 & 76.0 \\
Cushion & 40.2 & 52.3 & 64.4 & 76.6 \\
Overall & 39.8 & 52.0 & 64.2 & 76.4 \\
\hline
\end{tabular}

Table 4: Average temperature over (top) the occupied surface, and (bottom) the seat heater for the deformed occupant model.

\begin{tabular}{lllll}
\hline Occupied surf. temp. $\left[{ }^{\circ} \mathrm{C}\right]$ & $20 \mathrm{~W}$ & $40 \mathrm{~W}$ & $60 \mathrm{~W}$ & $80 \mathrm{~W}$ \\
\hline Backrest & 36.2 & 40.2 & 44.3 & 48.3 \\
Cushion & 37.6 & 41.5 & 45.4 & 49.3 \\
Overall & 37.3 & 41.2 & 45.1 & 49.1 \\
\hline
\end{tabular}

\begin{tabular}{lllll}
\hline Seat heater temp. $\left[{ }^{\circ} \mathrm{C}\right]$ & $20 \mathrm{~W}$ & $40 \mathrm{~W}$ & $60 \mathrm{~W}$ & $80 \mathrm{~W}$ \\
\hline Backrest & 38.2 & 50.5 & 62.8 & 75.1 \\
Cushion & 38.0 & 47.9 & 57.7 & 67.6 \\
Overall & 38.1 & 48.7 & 58.9 & 69.3 \\
\hline
\end{tabular}

Table 5: Temperature deviation with respect to the undeformed model results for (top) the occupied seat surface, and (bottom) the seat heater.

\begin{tabular}{lllll}
\hline Occupied surf. [\%] & $20 \mathrm{~W}$ & $40 \mathrm{~W}$ & $60 \mathrm{~W}$ & $80 \mathrm{~W}$ \\
\hline Backrest & 0.14 & 0.12 & 0.11 & 0.10 \\
Cushion & 0.72 & 0.60 & 0.53 & 0.49 \\
Overall & 0.62 & 0.56 & 0.49 & 0.45 \\
\hline & & & & \\
\hline Seat heater [\%] & $20 \mathrm{~W}$ & $40 \mathrm{~W}$ & $60 \mathrm{~W}$ & $80 \mathrm{~W}$ \\
\hline Backrest & 0.65 & 0.93 & 1.10 & 1.20 \\
Cushion & 5.68 & 9.25 & 11.6 & 13.3 \\
Overall & 4.54 & 6.69 & 9.07 & 10.3 \\
\hline
\end{tabular}

\section{CONCLUSIONS}

A comprehensive mechanical-thermal model was developed through material characterization and detailed simulation. The occupant seating pressure distribution was obtained through a participant-based postural study. The uniaxial compression experiments further revealed non-linear elastic behavior of the construction materials. In order accommodate non-linearity and variable pressure distribution in the simulation, the seat imprint was contourized, and effective elastic properties calculated at each contourized level. discretized level. Furthermore, the occupant was idealized as a constant temperature core with thermal resistances attached to the occupied seat surface, representing the skin, clothing, and contact. The majority of thermal resistance originated from the skin of the occupant. Finally, a comparison was made between thermal simulations with and without incorporating results from the mechanical study, to examine any notable differences.

It was found that the amount of insulation under the heater had a minor influence on the seat surface temperature. Similarly, occupant-induced seat deflection reduced of local thermal resistance atop the heater, the final heater temperature was also significantly reduced. In the mean time, there were negligible changes in the average occupied surface temperature, possibly due to the moderation of temperature through the human body core.

\section{ACKNOWLEDGEMENTS}

The authors would like to thank Materials and Manufacturing Ontario (MMO), and the Natural Sciences and Engineering Research Council of Canada (NSERC) for their financial support; W.E.T. Automotive Systems, Ltd., for supplying some of the material samples; Precision Design Systems, for providing the initial CAD drawings for the seat; Dr. Stuart McGill, David Bereznick, J. Kim Ross, for their assistance in the seating posture study; and finally, K. Douglas Hirst, Richard Morrison, and Norval Wilhelm, for their assistance in the elasticity experiments.

\section{REFERENCES}

[1] Thermal properties of tissue. Technical report, Department of atomic physics, Lund institute of technology, Lund, Sweden, 2003.

[2] S.D. Burch, S. Ramadhyani, and J.T. Pearson. Analysis of passenger thermal comfort in an automobile under severe winter conditions. ASHRAE Transactions, 98(1):247-257, 1992.

[3] P. Cheng. Heat transfer in geothermal systems. Advances in Heat Transfer, 20:893-898, 1978.

[4] P.O. Fanger. Thermal comfort: analysis and applications in environmental engineering. McGraw Hill, 1972.

[5] R.A. Haslam and K.C. Parsons. An evaluation of computer-based models that predict human 
responses to the thermal environment. ASHRAE Transactions, 94(1):1342-1360, 1988.

[6] G. Karimi, E.C. Chan, and J.R. Culham. Experimental study of thermal modeling of an automobile driver with heated and ventilated seat. In 2003 SAE Digital Human Modeling Conference, number 2003-01-2215, Montréal, Québec, 2003.

[7] G. Karimi, E.C. Chan, J.R. Culham, I. Linjacki, and L. Brennan. Thermal ocmfort analysis of an automobile driver with heated and ventilated seat. In SAE 2002 World Congress, Detroit, Michigan, 2002. 2002-01-0586.

[8] W.A. Lotens. Comparison of thermal predictive models for clothed humans. ASHRAE Transactions, 94(1):1321-1341, 1988.

[9] R. Ragan, T.W. Kernozek, M. Bidar, and J.W. Matheson. Seat interface presurs on various thicknesses of foam wheelchair cushions: a finite modeling approach. Archives of Physical Medicine and Rehabilitation, 83:872-875, 2002.

[10] B.A. Todd, S.L. Smith, and T. Vongpaseuth. Polyurethane foams: effecs of specimen size when determining cushioning stiffness. Journal of Rehabilitation Research and Development, 35(2):219-224, 1998.

\section{CONTACT}

Edward C. Chan, Research Engineer Microelectronics Heat Transfer Laboratory Department of Mechanical Engineering University of Waterloo

Waterloo, Ontario. N2L 3G1. Canada. Telephone: 1 (519) 888-4567 × 5612

e-mail: edward@mhtlab.uwaterloo.ca 


$$
\begin{aligned}
& 88 \\
& 88
\end{aligned}
$$




$$
\begin{aligned}
& 88 \\
& 86
\end{aligned}
$$

